\title{
Research of the Addiction of Negative Exercises in Xi'an Elderly
}

\author{
Yawei Han ${ }^{1, a}$ \\ ${ }^{1}$ Xi'an Eurasia University of Physical and Health Department, Xi'an, Shaanxi, 710065 \\ ${ }^{\mathrm{a}}$ email
}

Keywords: Psychology, The Elderly, Passive Exercise Addiction

\begin{abstract}
Moderate exercise is conducive to health, improve the body's immunity. However, excessive exercise can lead to decreased immune capacity, more severe cases can lead to exercise addiction. It analyzes the causes of negative exercise addiction is formed from a psychological point of view, to the elderly in Xi'an as the research object, and literature review, observation and questionnaire method, Xi'an elderly formed the genesis of negative exercise addiction analyze, draw conclusions for the elderly in Xi'an work, aspects of life and the family all the pressure, thereby forming elderly mental hostility, interpersonal sensitivity, paranoia and other unhealthy mental illness.
\end{abstract}

\section{Introduction}

With economic development and people's living standards, more and more people want to have a healthy body. Therefore, more and more people began to engage in sports. Around us is not difficult to see that sports figure, but people for physical exercise awareness is still stuck in improving health and enhance people's physical age, there are a considerable number of people began to frantically exercise, regardless of wind and rain, but also whether summer or cold winter. Such physical exercise for young people can afford, but for the Aged, is a hundred of harm.

\section{Theory}

Related Concepts. Exercise addiction: people regularly exercise psychological and physiological dependence on lifestyle.

Classification Exercise Addiction. Positive exercise addiction: you can control the exercise of human behavior, and actively exercise addiction can promote people's physical and mental development and mental health, regulate body functions, increase people's self-confidence and a sense of success and happy body and mind in a state of relaxation after exercise there are comfortable, relaxed state, this exercise addiction is a relatively healthy exercise addiction.

Negative exercise addiction: movement of physical and psychological dependence. The main performance of a single form of exercise every day must be a fixed timetable to exercise once the schedule break, you will feel uncomfortable. Sport above all else, will gradually put the motion as the first important thing to do in life, the high-intensity exercise endurance increased, leading to repeated movement cycle, once the motion stops, feel restless, like sports alone.

\section{Research Methods}

Literature. Access to relevant literature on exercise addiction found on exercise addiction is more common in developed countries, and for the study of the movement of its main mechanism of addiction based.

Questionnaire. In this paper, the development of a total of three sets of questionnaires, Terry is the first set of exercise addiction self-examination scale designed to measure whether the elderly in Xi'an have exercise addiction symptoms.

The second set is a symptom of self-examination scale, mainly compiled by the LR Derogatis, aims to analyze the symptoms of suffering from exercise addiction Xi'an elderly relative is not suffering from exercise addiction symptoms Xi'an elderly were compared in order to Xi'an elderly 
exercise addiction analyze reasons for the formation of symptoms.

The third set was to investigate suffering from exercise addiction symptoms Xi'an older people, namely to do more detailed understanding from the perspective of self-esteem, work, family, living conditions, as well as interpersonal and so on.

All data will be applied probability and finishing results more in-depth study of statistics, by observing the frequency of certain phenomena to discover the inherent laws of this phenomenon.

\section{Questionnaire Analysis}

The First Set of Questionnaires. The first set of questionnaire that is self-examination exercise addiction scale 196 valid questionnaires, obtained by testing 92 patients with exercise addiction, it has not come to exercise addiction 104 patients.

Second Survey. Symptoms effective self-examination scale copies 136 copies. Symptoms Scale in self-examination, we will exercise addiction in Xi'an elderly and non-elderly exercise addiction in Xi'an have carried out a questionnaire, which has a total of exercise addiction in Xi'an elderly 92, at 92 exercise addiction symptoms do survey questionnaire. Effective parts 81 parts 11 parts invalid copies, in the absence of motion exercise addiction in patients with symptoms of 104 Xi'an elderly do the survey, 100 valid copies, invalid four parts.

According to the above conclusion, the movement never become addicted patients with symptoms of 100 valid questionnaires, randomly selected self symptom scale survey number 81 and older has become a questionnaire exercise addiction of 81 elderly people were analysis.

Self-rated symptom scale test is always 90 , respectively corresponding to each option there is no, very light, medium, heavy emphasis. Option corresponds to a score of 1 point, 2 points, 3 points, 4 points, 5 points. It can be summarized as 10 factors, including somatization, obsessive-compulsive disorder, interpersonal sensitivity, depression, anxiety, hostility, terror, paranoia, mental, and others. Survey results are as follows:

Table 1 Xi'an elderly exercise addiction self-rated symptom scale

\begin{tabular}{|c|c|c|c|c|c|c|c|c|c|c|}
\hline & $\begin{array}{c}\text { Somatiza } \\
\text { tion }\end{array}$ & $\begin{array}{c}\text { Obsessiv } \\
\text { e-compul } \\
\text { sive } \\
\text { disorder }\end{array}$ & $\begin{array}{c}\text { Interpers } \\
\text { onal } \\
\text { sensitivit } \\
\mathrm{y}\end{array}$ & $\begin{array}{l}\text { Depressi } \\
\text { on }\end{array}$ & anxiety & hostility & terror & Paranoid & $\begin{array}{l}\text { Spirituali } \\
\text { ty }\end{array}$ & Other \\
\hline None & 17 & 3 & 0 & 0 & 0 & 0 & 0 & 0 & 0 & 5 \\
\hline Litter & 34 & 22 & 10 & 49 & 6 & 0 & 23 & 0 & 0 & 23 \\
\hline Middle & 24 & 10 & 10 & 14 & 10 & 11 & 43 & 12 & 15 & 33 \\
\hline Poor & 4 & 47 & 20 & 10 & 37 & 18 & 11 & 17 & 19 & 19 \\
\hline Worst & 2 & 0 & 43 & 9 & 19 & 53 & 5 & 53 & 48 & 2 \\
\hline
\end{tabular}

The following is the feeling, thinking, feeling, consciousness and other psychological factors of 81 are suffering from exercise addiction in Xi'an elderly were analyzed:

Table 2 Xi'an elderly exercise addiction self-rated symptom scale

\begin{tabular}{|c|c|c|c|c|c|c|c|c|c|c|}
\hline & $\begin{array}{c}\text { Somatiza } \\
\text { tion }\end{array}$ & $\begin{array}{c}\text { Obsessiv } \\
\text { e-compul } \\
\text { sive } \\
\text { disorder }\end{array}$ & $\begin{array}{c}\text { Interpers } \\
\text { onal } \\
\text { sensitivit } \\
\text { y } \\
\end{array}$ & $\begin{array}{l}\text { Depressi } \\
\text { on }\end{array}$ & anxiety & hostility & terror & Paranoid & $\begin{array}{l}\text { Spirituali } \\
\text { ty }\end{array}$ & Other \\
\hline $\begin{array}{l}\text { Poor and } \\
\text { Worst }\end{array}$ & 6 & 47 & 73 & 19 & 56 & 71 & 16 & 70 & 67 & 21 \\
\hline
\end{tabular}

The Third Set of Questionnaire. For the above four aspects respectively in Xi'an elderly have to do a more detailed investigation, study factors which affect mental health, paranoia, interpersonal sensitivity, hostility and other aspects of its work, family, life and education, aspects of the character, purpose and other sports to know, for example, interpersonal factors analysis, from the understanding of the family, it is from the parents and children as well as the relationship between love and family income, etc. for understanding. Analyze aspects of sports education purposes, the main sports addicts understand the profession and the qualifications analyzed, aspects of personality for the sports addicts self-assessment and evaluation as the subject with friends for the current state 
of motion satisfaction degree and other issues.

Questionnaire A total of 100 questions, divided into work, family, life, character, object movement in five areas, there are always small problems every aspect of the 20 components. Each option is a small problem were very satisfied, satisfied, in general, satisfied, very satisfied, and give corresponding scores are very satisfied with 5 points, 4 points satisfied, generally 3 parts, are not satisfied with 2 points, 1 is not satisfied .

Questionnaire is with the object 81 in Xi'an elderly exercise addiction. Questionnaire results: each questionnaire a total of 500 points, divided into 250 points, 81 sports addicts were less than 150 points, 68 points lower than 100 sports addicts. The number is less than $84 \%$ of the total number of 100 points.

The questionnaire respectively, from the perspective of five aspects of work-family life purpose and other sports personalities starting to analyze the 81 sports in Xi'an elderly patients are addicted negative spirituality, paranoid, interpersonal sensitivity, hostility four major psychological factors unhealthy . Specific Xu follows

It refers to morbid self-cited advantages ideas or delusions, commonly killed, love, hate, jealousy, honor, litigation, exaggerated and supernatural abilities beyond paranoia. However supernatural ability paranoia and exaggeration is prone to lead to exercise addiction psychological factors.

Three questionnaires were noted 81 elderly people and $16 \%$ of the elderly will be serious or paranoid emphasis on the phenomenon, however, it can be analyzed from the third questionnaires, paranoid 81 elderly people living in $45 \%$ of all work 15\%, households accounted for $16 \%, 21 \%$ sports purposes, personality aspects accounted for $55 \%$.

It can be seen, there is a paranoid situation of older persons, mainly in terms of personality, aspects of life and the purpose of the motion aspect.

From the aspect of character analysis of the formation of Xi'an elderly exercise addiction, mental paranoia occur for many reasons, the total is well known, each person's personality is different, this is not acquired through the efforts from mainly a congenital form. Character so people have a desire for success, sports addicts to break their own when faced with physical limits, it seems to play a different from ordinary people physical endurance or perseverance, will show greater desire for success, to break through the self physiological limit desire, which is formed regardless of the physical limits of form exercise addiction. So for paranoid personality on the terms of exercise addiction patients often pay more attention to the pursuit of success and exaggerated or feel even more strongly stimulated

Mental Xi'an elderly exercise addiction after bigoted reason analysis from the aspects of life, the elderly sports in life tend to have more or less self-centered or a macho movement in daily life addiction the elderly tend to account for a large dominant in life, it is generally desirable to not only control of their own bodily functions, you can also control the life of every little thing. So in life paranoid phenomenon mainly in the strong desire to control

Campaign aims to analyze the causes paranoid psychological aspect after the elderly of Xi'an to exercise addiction, people for the purpose of the movement is all sorts, someone may want to lose weight, some people would like to exercise, more people want to make friends. Therefore, the purpose of different sports have different state of motion, for example, hope that they can lose weight athletes, sport is at the initial stage, increase exercise intensity and range of motion, but in the mid and late sports movement will reduce the frequency of motion and movement strength, weight loss success, they tend to stop moving. To make friends for the purpose of athletes, it does not care about the strength of the movement, its main focus is movement time, movement is a necessary condition for the physiological addiction have a negative effect, impede normal growth and development of the body, so for making friends for the purpose of movement, the movement into a little sex addicts. For the fitness for the purpose of sport elderly, can easily form exercise addiction. Sports and fitness is immeasurable, it has no clear standard, so many elderly people who are unaware of their own motion, when the body has produced discomfort, still addicted to sports, nature and thus to exercise addiction.

People feel inferior, depressed and in relationships obviously do not get along, it can not deal 
with the relationship between the individual and society, there is a strong wary of people in the process along, the jealousy and the like.

Three questionnaires were noted in Xi'an 81 elderly patients were in the process of movement accordingly interpersonal sensitivity were manifested in life, family, work, personality and sports purposes.

In life sports addicts interpersonal sensitivity, mainly in that it can not handle the relationship between social groups and, according to investigation sports addicts tend to be more extreme in life, to do things than normal impulsive, irritable, irascible. So often there will be bad interpersonal phenomena, including with friends, as well as closely related to the life of people, often this interpersonal sensitivity can lead to exercise addiction patients are willing to put more time and energy into movement, ignored the capacity of the body, leading to a vicious cycle, until the generation of exercise addiction.

In the family sports addict interpersonal sensitivity, and mainly in that it can not be a better family communication. In the early movement, exercise addiction in the family relationships of patients would be less sensitive, but with increasing exercise intensity and effort put in motion increases, interpersonal sensitivity will become more and more intense, the most resulting in the generation of exercise addiction, the reason mainly lies in the early movement, exercise addiction patients and their families with less communication, and sports professionals to communicate, causing heavier tragedy generated.

Mainly includes three aspects, the behavior of thoughts and feelings, mainly disgust, threw things around, the emotional aspect of the debate until uncontrollable temper outbreaks.

Three questionnaires were noted 81 in Xi'an elderly sports addicts there is a corresponding hostility in the course of the campaign, they were manifested in terms of family life and sports and other purposes.

In life sports addicts in life, mainly in its aversion to all things in life, for the movement as the only way of entertainment, sports will be seen as life necessities. Exclusion of other life can form of entertainment. All the energy is into motion to go. Usually athletes have more entertainment, such as shopping, chatting, eating, watching movies, entertainment and sports addicts whose only one way, is exercise.

In the family sports addicts, mainly for all the hostility against the family members of its movement, is well known, the family is the people in the world, recently loved ones, family members will pay a lot for us, under normal circumstances, patients gradually in exercise addiction during the formation of exercise addiction, the family soon found that most families would advise patients with less physical activity and exercise addiction exercise intensity, exercise addicts start will not listen to advice. However, with the increasing amount of exercise, family opposition has also increased, and therefore will be issued to the family form a hostile relationship

Hostile relations in terms of the purpose of the movement, in the movement of patients in addiction, mostly male patients exercise addiction, to study the causes of departure from exercise addiction sports purposes, you can see the different men's and women's sports purpose sports purposes. Women in the East are more focused on the purpose of weight loss, while men focused on the purpose of the movement of various ideological confrontation. For example, said long-distance marathon runners and fellow basketball against male athletes, and their own or confrontation. Their male sports addicts in the early movement to participate in sports, there will be ambition and hostility. Therefore, in terms of purpose motion movement object of male than female sports purposes more emphasis on the struggle and hostility.

\section{Conclusion}

Xi'an elderly who are suffering from exercise addiction psychologically is paranoia, hostility and other psychological unhealthy psychological sensitive relations symptoms. Heart unhealthy symptoms are in the family, aspects of life and sports purposes and so on. Patient motion addiction can communicate with their families and more fully understand their own physical fitness, reduce the amount of exercise, a reasonable allocation of their free time, all the time we can not exercise 
enough to cultivate other hobbies and other measures to reduce exercise addiction symptoms.

\section{References}

[1] Ma Yan. Look from the perspective of physiological health effects of exercise addiction [J]. Liupanshui Higher Academy Sinica, 2012, 05: 321-424.

[2] Li Geang. About sports and health survey in the study population exercise addiction and coping strategies [J]. Northwest Normal University, 2012, 08: 89-91.

[3] Xie Songlin, Li Wei. Exercise addiction Review [J]. North China Normal University, 1999, 08: 621-724.

[4] Zhang Rui. Exercise Physiology Research Addiction Review [N]. First Financial Daily, 2003

[5] Qin Dongying. Excessive exercise or sports addiction to sedentary people to be vigilant against [N], Liberation Daily. 2011.

[6] Lu Qibao, Li Shao. Group movement mo "addiction" [J]. Sports mentorship, 2005, 6: 1.

[7] Xie Songlin. Research Movement addictive behavior [D]. South China Normal University, 2013.

[8] Wang Hongyan. Exercise addiction and related research [D]. Southwest University .2012.

[9] Zongdingfa. Exercise addiction health benefits [J]. Family Medicine, 2004, 7: 2.

[10] Zhang Rui, Guo Haixin. Study the physiological mechanism, exercise addiction comments [J]. Yanbian University, Jan. 2009: 25.

[11] Xue Weisan. Movements that addiction is good [J]. New Sports, 2009, 04: 1.

[12] Li Yonghui, Sui M Psychological dependence drug addiction and relapse of brain mechanisms [J]. Advances in Psychological Science, 2006, 04: 14.

[13] Feng Juan Juan, Sun Xiulan. Negotiations and Social Psychology [D]. Negotiation, economics Publishing 2008.

[14] Bu Guohua. Sports addiction is not a good thing [J]. China Sports Daily, 2008,11: 7.

[15] Ning Yixue. Unhealthy addiction snow sports [J]. Metropolis Daily supplements, 2009,48: 2.

[16] Zhang Hua. The secret lies in the motion why addictive endorphins and dopamine [N]. Evening, 1996.

[17] Li Zhangrong. Beautiful girl in a marathon tour of the West Lake with the help of powder: so addictive games [N]. Evening News, 2014.

[18] Gan Meirong. Do you have sports addiction it? [J]. Health Sciences, 2003, $02: 1$. 